\title{
Comment
}

\section{Os Desafios da Educação Especial}

\author{
Robério Bezerra Leite ${ }^{1}$; Gislene Farias de Oliveira ${ }^{2}$
}

\begin{abstract}
Resumo: O presente artigo tem como objetivos, discutir os caminhos da educação especial ao longo da história e sua atual legislação; comparar as diferenças entre necessidades educativas especiais e deficiência, bem como identificar à luz da literatura, os conceitos de inclusão e integração. ; qual o papel do professor frente a essa nova realidade. Justifica-se o presente estudo por elucidar a papel do professor frente a nova realidade quanto a educação especial no Brasil. Os resultados nos levaram a crer que ainda é necessário que a inclusão seja mais efetiva nas escolas, não fique apenas nas leis, mas que a comunidade faça valer seus direitos cidadãos, diminuindo o preconceito e melhorando a qualidade da educação daqueles alunos com necessidades educativas especiais.
\end{abstract}

Palavras chave: Inclusão; Educação; Especial.

\section{The Challenges of Inclusive Education}

Abstract: This article aims to discuss the paths of special education throughout history and its current legislation; Compare the differences between special educational needs and disability, as well as identify in the light of the literature, the concepts of inclusion and integration.; What is the teacher's role in facing this new reality. The present study is justified in elucidating the role of the teacher in face of the new reality regarding special education in Brazil. The results have led us to believe that inclusion is still necessary to be more effective in schools, not just in laws but that the community assert its citizens' rights, reducing prejudice and improving the quality of education of those students with special educational needs.

Keywords: Inclusion; Education; Special.

\section{Introdução}

A crença de todo ser humano é de ter acesso igual para todos independente de sua classe social ou deficiência sendo ela física ou motora. A diferença social na nossa sociedade é bastante antiga, desde primórdio da nossa civilização principalmente no âmbito escolar, por isso se faz necessário uma transformação nas nossas instituições de ensino. Pois todos nós temos o direito de sermos diferentes, pois somos todos seres humanos.

\footnotetext{
${ }^{1}$ Mestrando em educação pela Anne Sullivan University - Polo Juazeiro do Norte . E-mail: roberio.bezerra@yahoo.com.br;

2 Psicóloga. Doutora em psicologia Social pela Universidade Federal da paraíba - UFPB. Pós Doutorado em Ciências dea Educação pela Faculdade de medicina do ABC - SP. Professora da Universidade Federal do Cariri - UFCA. E-mail: gislenefarias@ gmail.com.
} 
Id on Line Revista Multidisciplinar e de Psicologia

Id on Line Multidisciplinary and Psycology Journal

O fato de ser bonito ou feio, magro ou gordo, inteligente ou não, ter duas mãos, e assim sucessivamente, nada disto nos faz diferentes, continuamos e permanecêssemos iguais. A diferença esta apenas em elevar a sua capacidade intelectual que pode nos levar as mais altas particularidades.

Este é o lado positivo da diferença. Porém, assim como a igualdade, a diferença pode nos ajudar ou prejudicar. Por isso, temos o mesmo direito a sermos iguais e a sermos diferentes. "Temos direito de ser iguais quando a diferença não inferioriza e direito de ser diferentes quando a igualdade nos descaracteriza”. (SANTOS, 2005, p. 2).

Dentro dessa perspectiva, a escola não pode mais ignorar os fatos, ela é uma visão clássica da sociedade, se a sociedade muda, a instituição escolar tem que mudar, se a sociedades somos todos, a escola é para todos.

[...] é necessário introduzir mudanças tanto nas escolas especiais como nas regulares [...] Há muitas indicações de que em um número elevado de países de todo o mundo a integração é um elemento central na organização da educação especial [...]. Esse projeto parece adequado para os países do Terceiro Mundo, dada à magnitude das necessidades e as inevitáveis limitações de recursos disponíveis (AINSCOW, 1995, p. 18).

A escola tem que ser acolhedora e abranger não somente as classes centrais mais também as áreas periféricas, tendo em vista que a maioria das escolas especiais atendia apenas uma pequena parcela desse novo público.

A Declaração de Salamanca, fruto da "Conferência Mundial sobre Necessidades Educativas Especiais: acesso e qualidade”, ocorrida na Espanha, em 1994:

\begin{abstract}
A experiência, sobretudo nos países em via de desenvolvimento, indica que o alto custo das escolas especiais supõe, na prática que só uma pequena minoria de alunos [...] se beneficia dessas instituições... [...] Em muitos países em desenvolvimento, calcula-se em menos de um por cento o número de atendimentos de alunos com necessidades educativas especiais. A experiência [...] indica que as escolas integradoras, destinadas a todas as crianças da comunidade, têm mais êxito na hora de obter o apoio da comunidade e de encontrar formas inovadoras e criativas de utilizar os limitados recursos disponíveis (DECLARAÇÃO DE SALAMANCA, 1994, p. 2425).
\end{abstract}

Essa declaração mostra o quanto é caro mante uma instituição especial, as escolas devem atender e acolher essas crianças, independente de suas condições seja elafísica, emocional ou intelectual.Sobre a visãoimpactante desse documento e dentro de uma estrutura das políticas 
sociais, um discurso de "educação inclusiva" toma um contexto maior no país, de modo que profissionais que atuavam na Educação Especial passam, a utilizar o termo "inclusão" no lugar de "integração".

\begin{abstract}
Mas temos que pensar que para que a inclusão se efetue, não basta estar garantido na legislação, mas demanda modificações profundas e importantes no sistema de ensino. Essas mudanças deverão levar em conta o contexto sócio.econômico, além de serem gradativos, planejadas e contínuas para garantir uma educação de ótima qualidade (Bueno, 1998, p. 16).
\end{abstract}

A instituição escolar inclusiva deve ser eficiente, estruturada, aberta e, com certeza, atrairá vários benefícios para essa nova clientela que já foi muito excluída, e perdendo muitas das vezes o direito de estudar. A escolar tem o dever de contribuir para uma educação inclusiva e fazer com os mesmo sejam atores participativos e atuantes na filosofia escolar, visto que a escola é o principal suporte desses indivíduos.

\title{
O Desafio da Inclusão
}

Traçar um plano de inclusão é algo que precisa ser pensado e planejado, bem como desenvolver politicas claras de que demanda um processo complexo e, sobretudo, fundamental no espaço educacional" Janilcélia de Fatima Neves (Diretora de escola da Rede Municipal de ensino - SP).

O processo de inclusão já é um conceito mundial onde as pessoas com deficiências lutam por seus direitos e um lugar na sociedade. Mas será que as pessoas realmente sabem o que é esse termo que é tão falado e discutido ultimamente. O que de fato e inclusão?

O termo em si já nos remete uma ideia de exclusão, pois sóhaverá inclusão se houver excluídos. O debate sobre esse tema é bastante complexo, principalmente no ambiente escolar, que tem recentemente, exigido propostas pedagógicas que assegurem oportunidades e direitos iguais para todos os alunos, coisa que não é fácil, tanto pela estrutura física como pela estrutura humana, pois nem as escolasnem os docentes estão preparados para essa nova clientela. Conforme nos assegura Stainback (2004/2005, p. 20-24). 
Um dos motivos da escola não efetuar com êxito o processo de inclusão ocorre pelo fato da padronização dos programas de ensino, da avaliação e dos métodos educacionais que, segundo ela, ignoram a diversidade sócio - cultural dos alunos.

Podemos concluir que o professor pode gerenciar as suas metodologias de ensino buscando entender as culturas diferentes e assim ter um conhecimento prévio de cada um dos seus alunos.Mais observamos muito as dificuldades enfrentadas pelos professores, principalmente em suas falas: "não sou capaz disso", "não sei por onde começar", "não fui preparado pra isso", não temos estrutura pedagógica para nos auxiliar”, "a turma não vai aceitar esse aluno", "ele vai si sentir excluído", "como avalia-lo"....

Segundo Figueira, (1995, p. 21).

Palavras são expressões verbais de imagens construídas pela mente. As vezes, o uso de certos termos, muito difundido e aparentemente inocentes, reforça preconceitos. Além dessas falas, temos observado, o medo da mudança com certeza do fracasso e medo da diferença onde se sentem ameaçados, os que provocam afastamento, o estigma e consequentemente o preconceito. O professor desconhece quem é este sujeito, suas possibilidades, seus desejos, suas dificuldades e limitações.

Fica explicito o grande desafio da instituição de ensino escolar, que tem que enfrentar diversas dificuldades para poder proporcionar um ensino igual para todos independente de suas diferenças.

A escola tem um papel importantíssimo para que ocorra uma mudança significativa do ponto de vista da inclusão irrestrita, para que isso se efetive de fato é de suma importância que os professores, se reconheçam como pessoas capazes de mudar essa realidade na pratica pedagógica.

Devemos respeitar a individualidade de cada membro em relação à aprendizagem e garantir o atendimento educacional especializado, ter um projeto politico pedagógico que possibilite essa educação de qualidade, valorizando o profissional da educação para que o mesmo participe ativamente da construção desse projeto, para que a escola passe a ser o lugar atrativo, fazendo assim com que haja uma interação do aluno com a realidade sócio -cultural, pois uma escola de qualidade valoriza o que o aluno aprende o que descobre e o que criam. 
Id on Line Revista Multidisciplinar e de Psicologia

Id on Line Multidisciplinary and Psycology Journal

\section{Conclusão}

Ao estudar sobre a inclusão, voltado para a inclusão escolar, chegamos a um resultado, para que ela aconteça temos que ter uma mudança no sistema de ensino. Essa mudança tem que ter uma característica de especialização, ou seja, adequa-se a todos os alunos e não apenas aquelas tidas como especiais, para que isso realmente ocorra é necessário a participação e esforço de todos no processo de inclusivo.

É necessária a evolução de todos, desde o porteiro a merendeira e principalmente do professor que é o mediador essencial para que o aluno se sinta acolhido e possa assim participar ativamente das atividades pedagógicas proposta pelo educando, devemos lembrar que teremos que ter uma participação coletiva para que o objetivo seja alcançado com êxito. Kunc (1992) já nos orientava que a inclusão é um excepcional e necessário fundamento para a valorização das diferenças, inerente a raça humana. A idéia de educação inclusiva, traz em seu arcabouço a desmistificação da dualidade sobre normal e anormal, de forma a empoderar o ser humano de suas características e diferenças, saudáveis para fortalecimento da convivência e do respeito.

Nesse contexto devemos, valoriza-se os valores humanos como o respeito, a solidariedade e a compreensão de que o outro tem suas próprias características, e isso o torna simplesmente mais humano. Ao professor, cabe a utilização de metodologias mais ativas e flexíveis, levando em conta as limitações e possibilidades de cada individuo.

\section{Referências}

AINSCOW, M. Necesidades especiais em sala de aula. Guía para la formación del profesorado. Paris: UNESCO; Madrid: NARCEA, 1995.

DECLARAÇÃO DE SALAMANCA. Princípios, Políticas e Prática em Educação Especial. Espanha, 1994.

BUENO, Belmira; CATANI, Denice; Sousa, Cynthia (Orgs.). A vida e o ofício dos professores. São Paulo: Escrituras, 1998.

STAINBACK, Susan Bray. Entrevista - Revista pedagógica. Ano VII, no 32, nov.2004 - jan. 2005. Porto Alegre:Artmed, 2004, p. 20 - 24. 
FIGUEIRA, E. A Imagem do Portador de Deficiência Mental na Sociedade e nos Meio de Comunicação - Ministério da Educação - Secretaria de Educação Especial, 1995.

KUNC, N. - The Need of belong. Rediscovering Maslows Hierarchy of Needs in Villa, J.J. Thousand, W. Stainback E S. Satinback - ReestructuringFor Caring And Effective Education: Na Administrators Guide To Creating Heterogeneous Schools. Baltimore, Paul H. Brookes, 1992, p. 1-39.

\section{Como citar este artigo (Formato ABNT):}

LEITE, R.B.; OLIVEIRA, G. F. Os Desafios da Educação Inclusiva. Id on Line Revista Multidisciplinar e de Psicologia, Janeiro de 2017, vol.10, n.33, p. 347-352. ISSN: 1981-1179.

Recebido: 07/12/2016

Aceito: 12/12/2016 